\title{
Message of greetings to the Robotics Society of Japan
}

The president of the RSI

Manjit Singh

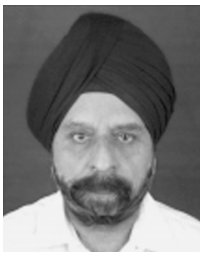

I am very happy to extend our greetings to the Robotics Society of Japan (RSJ) on their 30th anniversary. The past thirty years has seen RSJ contributing immensely not only to Japan but also to the world robotics community, in the form of journals, conferences, workshops etc. Indian robotics researchers have also benefited from interaction with RSJ in many ways. The Indian Robotics Society, as a new member of the Asian Robotics Society Union, hopes that together we would contribute towards enhancing robotic applications in education, industry, society etc. in the near future. Asia today is the largest user of robots, and ARSU could be the best platform to collaborate between various countries. I am sure that RSJ would continue to grow and contribute extensively to the robotics community in future.

\section{Brief introduction to the Robotic Society of In-} dia

In the last few years robotics activities in India has moved well beyond the traditional areas of industrial applications, atomic energy, etc. and entered newer domains of education, rehabilitation, entertainment, and even into our homes. Indian robotics researchers have similarly grown from a handful to over a hundred engaged in research labs, education, industry, atomic energy, etc. Many researchers feel that it is about time to form an academic society to further augment robotics activities and for better interaction. With this objective the Robotics Society of India was formed on 10th July 2011 (www.rsindia.org). As of today we have about 100 members and is increasing rapidly. The main objectives are:

- Encourage interaction between robotics researches in India (academic/R\&D Labs/industry).

- Hold joint workshops and conferences at the national level.

- Associate with other organizations involved in Robotics like IEEE, ASME, ARSU.

- Publish a newsletter, proceeding, Journals, etc. 